Night BLINDNESS

\title{
NIGHT BLINDNESS
}

BY

\author{
KathaRINE TANSLEY
}

LONDON

FROM THE DEPARTMENT OF PHYSIOLOGY, PHARMACOLOGY AND BIOCHEMISTRY, UNIVERSITY COLLEGE LONDON

THE interest which has recently been focussed on the problems of nutrition has resulted in a widespread search for quick, easy and reliable methods for measuring small degrees of dietary deficiencies.

Although the connection between vitamin A deficiency and night blindness has been well established for some time, it is only quite lately that the taking of dark adaptation curves has been much used as a test for slight degrees of malnutrition due to a deficiency of this vitamin. Unfortunately, by far the greater part of the work done on these lines is entirely unsatisfactory from the visual side-in fact it is probably not going too far to say that most of the dark adaptation curves, taken with a view to estimating the degree of vitamin A deficiency in a given individual, are quite worthless.

This deplorable state of affairs seems to be due to the sudden incursion of clinicians and vitamin workers into the highly specialised field of subjective visual research. The necessity for some previous training in what is, after all, an extremely complicated and difficult experimental method has not, apparently, been realised. In some cases, even, the very reasons for using a dark adaptation test at all for the measurement of vitamin A deficiency seem not to have been fully understood.

The purpose of this paper is to restate, as simply as possible, what we know about night blindness and why we should expect one type of this disease to be curable by vitamin A therapy. It is not intended to indulge in an exhaustive criticism of the work that has already been done but rather to point the way to that better general understanding of the whole subject without which really satisfactory work cannot be achieved. A few general criticisms of the methods at present in vogue will be found at the end of this paper.

It is on circumstantial evidence only that we base the belief that our visual perceptions at low illuminations are the result of the reactions of visual purple to light. If, however, we take all the facts together not only do they make an extremely convincing case, but; up till now, nothing has emerged from the study of visual purple which might cause us to look on this theory with suspicion. 
The duplicity theory is, in the main, the work of three menSchultze (1866), Parinaud (1881) and v. Kries (1896), but it is probably easier to show on what exactly we base the complete theory to-day if we neglect the chronological order of the various discoveries and take the steps in the order in which they make the most connected story.

The duplicity theory has to explain why there are such remarkable differences between our vision at illuminations over 0.01 f.c. (day vision) and our vision at illuminations below this level (night vision). At high illuminations we can appreciate colour (differences in wave length) and the most sensitive part of the retina is the fovea which we use for all activities requiring distinct vision. At low illuminations we are colour blind and find that, while the fovea is comparatively insensitive, the sensitivity of the peripheral retina is enormously increased. In day vision the brightest part of the spectrum appears to be in the "yellow," but at night, while the spectrum is appreciated in shades of grey only, the brightest part has shifted to the "green" and the "red" is entirely invisible. This change-over is known as the Purkinje (1825) phenomenon and occurs only in the periphery. At low illumination the fovea is unable to see the spectrum at all until it is made bright enough for the colours to appear. Even in day-light vision the extreme periphery of the retina is practically colour blind. The first step, then, connects the fovea with the acute coloured vision characteristic of high illuminations, and the peripheral retina with the colourless vision of low ones. The fovea is most sensitive to a wave-length of $555 \mathrm{~m} \mu$ (yellow), but can be stimulated by all parts of the visible spectrum while the periphery (in the dark adapted eye) is most sensitive to those between 500 and $505 \mathrm{~m} \mu$ (green) and not at all to those longer than $650 \mathrm{~m} \mu$ (red).

Careful microscopic study of the retina reveals that the fovea and periphery are of different histological composition. The fovea is made up entirely of cones while around it the cones become mixed with rods and, in general, as we go farther out towards the periphery the relative number of rods to cones becomes progressively higher. In the human retina the actual number of visual elements decreases towards the periphery so that although the ratio of rods to cones increases the actual rod count is highest in a ring at about $20^{\circ}$ from the fovea (Osterberg, 1935). Therefore, the second step in our chain of evidence connects the cones with day vision and the rods with night vision. This view is borne out by the fact that animals that live mostly by night or in dark places have a great predominance of rods in their retinae while animals that spend much time in the sun have mostly cones. This relationship between the rod and cone content of the retina and habit has been well demonstrated by Detwiler (1923) and 
Kolmer (1930) on lizards and primates respectively (see also Walls, 1934).

According to our present ideas an end-organ must contain a photo-chemical substance if it is to be capable of stimulation by light, and this is where the story comes to an end, for the present, as far as the cones are concerned for although Studnitz (1932 and 1937), Wald (1937), and Chase (1938) all claim to have extracted a pigment from the cones the amounts have been so small that no satisfactory investigation has so far been possible. Incidentally it appears that these three workers are not all dealing with the same pigment.

Boll (1876) first observed a red pigment in the retina which was bleached by light but it was Kühne (1877) who called it visual purple and showed that it was to be found in the rods only and that the retinae of animals in which rods predominate were particularly rich in this substance. He was unable to find any in the retinae of those species of snake and lizard which he examined. Later Köttgen and Abelsdorff (1896) plotted the absorption curve of visual purple and Trendelenburg (1911) made a curve of the bleaching power of different wave-lengths for visual purple. Both these curves practically coincide as one might expect from Draper's Law but they also agree pretty well with the curve of the sensitivity of the dark adapted eye to the different parts of the spectrum. Thus, corresponding to the maximum sensitivity of the rods to the green and the absence of sensitivity to the red wave-lengths visual purple is most readiiy bleached by green and is unaffected by red light. König (1894) also pointed out the significance of the similarity of the absorption curve of visual purple to the luminosity curve of the dark adapted human eye. Recently Dartnall and Goodeve (1937) have recalculated the luminosity curve at low illuminations on a quantum basis and compared the results with Lythgoe's (1937) visual purple absorption curve. They have found these two curves to be practically identical. So our third step connects the bleaching of the photo-chemical substance, visual purple, with vision at low illuminations.

In the eye visual purple is bleached by light but reappears slowly in the dark (Kühne found two hours necessary for regeneration in the frog and 38 minutes in the rabbit); at the same time the eye becomes slowly more sensitive during a stay in the dark and, therefore, since the effect of a given amount of light on a photochemical substance is proportional to the concentration of the substance it seems probable that the regeneration of visual purple is responsible for dark adaptation.

The condition known as night blindness is simply a failure in dark adaptation. In some cases the failure appears to be due to a slowing of the process and the patient merely takes longer to 
reach the normal level, while in others the normal level is never reached at all. v. Kries himself considered that night blindness was caused by a failure of the rod apparatus just as complete colour blindness was due to a failure of the cones. Parinaud did a good deal of work on the light sense and colour sense in night blindness and considered that the relations found in this disease formed one of the most essential supports of the duplicity theory. He believed the poor dark adaptation in this condition to be due to a faulty regeneration of visual purple which prevented the eye from reacting to low illuminations.

Night blindness has been recognised since pre-Christian times, and there is an immense body of literature from all over the world describing its symptoms and treatment. There have been many contradictory theories and much controversy as to the aetiology of the disease but we can now divide the cases into two main groups-those in which the night blindness has, so far, proved incurable and those in which it can be cured. Both simple congenital night blindness and the night blindness which characterises the early stages of retinitis pigmentosa, come into the first group while the night blindness sometimes associated with jaundice, with diseases of the liver or with malnutrition, come into the second. In the cases which may be included in the first category the retinal defect seems to be due to an abnormality of the rod cells themselves while in those belonging to the second the defect appears to be in the visual purple mechanism and the rods may be otherwise perfectly normal.

No histological examinations of the retina in cases of congenital night blindness have been made but in retinitis pigmentosa it seems to be established that the rods are the first cells in the retina to be affected (Treacher Collins, 1919, Verhoeff, 1931). Unfortunately there are no preparations available of eyes in which the disease is still in the early stage where night blindness is the only symptom. In a strain of rats which bear an hereditary disease of the retina histologically indistinguishable from human retinitis pigmentosa it has been shown that the earliest detectable change is the death of the rod cells and that visual purple is still present in the degenerate outer limbs several weeks after every rod nucleus in the retina is dead (Bourne, Campbell and Tansley, 1938). It is obvious, therefore, that it is futile to attempt to cure the night blindness of retinitis pigmentosa by treatment with carotene or vitamin A, since although these substances can improve the production of visual purple where this is deficient they are unable to repair degenerated rods (Tansley, 1936). It has, in fact, been shown that injections of carotene have no effect on the development of the retinal degeneration in rats (Bourne and Tansley, unpublished observations).

The night blindness which may occur in jaundice or in liver 
disease seems to be due to the same cause as that which is produced by malnutrition-namely vitamin A deficiency-and in all these conditions the defect can be cured by vitamin A therapy. In obstructive jaundice the trouble seems to be due to a deficient absorption of fats and therefore of vitamin $\mathrm{A}$ and carotene from the intestine (Blegvad (1924), Greaves and Schmidt (1935)) and it may be necessary to give injections of vitamin $A$ although the visual symptoms disappear if the jaundice clears up (Baas, 1894, Hess, 1909, Bloch, 1924, and many others). It has been observed by Wright (1931) Owen and Hennessey (1932) and others that symptoms of vitamin A deficiency, including night blindness, may appear in an apparently well-nourished individual as a sequel to liver disease. In these cases the liver appears to be unable to convert the carotene of the diet into vitamin $A$.

Another condition which may be associated with night blindness is pregnancy but only if the diet is rather poor in vitamin A. The reason seems to be that the female requires more vitamin $A$ during pregnancy and a dietary level which is sufficient for good health normally may not be high enough under the added burden of providing for the foetus (Tansley, 1936). Many cases of night blindness during pregnancy were reported from Vienna during the famine years after 1918 (Birnbacher and Klaften, 1923, Klaften, 1923).

The connection between night blindness and vitamin A deficiency is now so well established and so widely accepted that it is not necessary to go into the literature here, fascinating though much of it is. It has been known all over the Old World for many hundreds of years and especially to primitive peoples that night blindness cán be easily and rapidly cured by eating liver, and during the last twenty years it has been established that it is the vitamin A present in liver which is the curative factor. Holm (1925) and Sugita (1925) both demonstrated that vitamin A deficient rats were not able to get about at low illuminations as well as normal controls, and lately Hart and his co-workers in California (Hart, Mead and Guilbert (1933), Guilbert and Hart (1934 and 1935), Hart and Guilbert (1937), and Guilbert, Miller and Hughes (1937)), in a series of magnificent investigations into vitamin A deficiency in domestic animals have come to the conclusion that night blindness is the very first symptom of this condition and that the vitamin level which can just protect an animal represents the true physiological minimum requirement.

Since vitamin A deficiency causes night blindness both in man and animals one would expect it either to affect the production of visual purple in the dark-adapted retina or to cause degeneration of the rods. The rapidity with which nutritional night blindness can often be cured with vitamin A (Aykroyd, 1930), would 
indicate that the effect is more likely to be on the visual purple, since the repair of a damaged tissue would be expected to take more than a few hours. In point of fact it has been shown experimentally that the regeneration of visual purple is retarded and may be prevented as a result of deprivation of vitamin A. Fridericia and Holm (1925) found that the increase in visual purple content of the retinae of vitamin A deficient rats during a stay of three hours in the dark was always lower than that of normal controls. They compared the colours of the whole retinae with a modification of Garten's (1906) colour chart of the bleaching of visual purple. Their results were confirmed by Tansley (1931) who measured the optical density of visual purple extracts at intervals during dark adaptation. In this way curves for the regeneration of visual purple in normal and deficient rats were obtained and the latter always showed a decreased production of visual purple during a stay in the dark. Incidentally, the regeneration curve for normal rats obtained by Tansley was very similar to the human dark adaptation curve and therefore provides another piece of evidence that dark adaptation is due to the regeneration of visual purple. It has also been shown (Tansley, 1933 and 1936) that vitamin A deficiency prevents the production of visual purple in the developing eye and that although it may cause slight degenerative changes in the rods these are always a later development. There is a possibility that if the deficiency is allowed to become severe enough to affect the rod structure the resultant night blindness is, in fact, incurable (Hart and Guilbert, 1937, and Tansley-unpublished observations on Hart's material).

It is now necessary to inquire into the mechanism by which vitamin $\mathrm{A}$ is able to affect the production of visual purple. Holm (1929), in a paper which has not received the attention it deserves, was probably the first to suggest that visual purple may be closely allied to vitamin A and may, in fact, be formed from it. He was not, however, at all certain that this is the case since vitamin A and visual purple have such different chemical properties and since visual purple can be found in vitamin A deficient retinae provided the animals have been kept in the dark during the period of deprivation.

Wald (1935) as a result of experiments on the pigments which can be extracted from light and dark adapted retinae produced a scheme for the production and breakdown of visual purple. He believed that visual purple is a protein conjugated with a prosthetic group, the action of light being to split the molecule at this connection. Further, he stated that this breakdown produces a protein and a carotenoid pigment which he called retinene, and that retinene then forms vitamin A by an ordinary chemical reaction. This vitamin A can recombine with the protein in the 
dark and visual purple is formed again. This is an extremely attractive theory but unfortunately it still remains unconfirmed. Krause and Sidwell (1938) could find no evidence that vitamin A is produced as a result of the breakdown of visual purple and although they also believe that visual purple is a conjugated protein they are doubtful whether the prosthetic group is, in fact, a carotenoid. Recently (1938) Wald has modified his original theory thereby bringing it more into line with the results of other workers.

It should now be clear why the measurement of dark adaptation might be expected to give information as to whether or no an individual is satisfactorily provided with his vitamin A requirements. In an investigation on human subjects made deficient in this vitamin Booher, Callison and Hewston (1938) have clearlyt shown that the dark adaptation curves are affected and further that they can be brought back to normal by the administration of vitamin A. Haig, Hecht and Patek (1938) have taken dark adaptation curves from a patient suffering from cirrhosis of the liver and therefore probably from vitamin A deficiency as well. They found that the adaptation of this patient was markedly inferior to that of normal subjects but that it could be brought up to the normal level by injections of vitamin A. Both these groups of workers found that although the deficient curves are inferior to the normal ones at every point during a stay of thirty minutes in the dark the differences are far more obvious at the end of the experiment than at the beginning and Booher and her co-workers definitely point out the danger of trying to estimate the degree of vitamin A deficiency, particularly where this is slight, on the basis of readings taken after a short period of dark adaptation.

Many workers mostly in America, Denmark and this country (Frandsen 1934, Jeans and Zentmire 1936, Jeghers 1937, Edmund and Clemmesen 1937, Maitra and Harris 1937, Mutch and Griffith 1937 , and others) have attempted to evaluate the extent of vitamin A deficiency in sections of the population by the examination of the dark adaptation of large numbers of individuals and have all come to the conclusion that there is a widespread failure to reach a satisfactory standard. Unfortunately the experimental procedure of much of this work is open to serious criticism and the results have not been confirmed by other workers whose investigations have been more carefully controlled (Ehlers 1937, GrothPeterson 1938, Palmer 1938). Some of the more obvious criticisms may be mentioned here. In many cases the subjects are only tested twice, once to get the initial level and once more after vitamin A therapy and it is not surprising that the second readings should be better than the first since there is known to be improve- 
ment with practice. Again there seems to be no appreciation of the wide individual and day to day variations which are found even in subjects who have been provided with good doses of vitamin $\mathrm{A}$ for some time before the curves are taken. The effect of the general level of light adaptation, which often depends on the weather and which seems to influence the results even when a preliminary exposure to high illuminations forms part of the experiment, has not been taken into account. Another important factor, which has been almost completely ignored, is the aperture of the pupil which is normal to the subject during light adaptation. This has been found to be the chief cause of variation in the dark adaptation curves of a collection of normal subjects all of whom were provided with extra vitamin A before they were investigated. (Investigation of the dark adaptation curves of medical students at University College, London, by L. R. Phillips.)

Also, in spite of the fact that vitamin A deficiency is known to have much less effect on the early than on the later part of the dark adaptation curve, most of the measurements have been made during the first ten minutes in the dark in order to save time. It has already been mentioned that Booher, whose work has been unusually carefully 'done, does not consider that these early readings can give satisfactory results.

Vitamin A deficiency is believed to result in poor dark adaptation because it causes a poor regeneration of visual purple in the retinal rods, yet most of the investigations have, in fact, been made under conditions where the central part of the retina, which contains no rods, must be used! In point of fact, this criticism is not so serious as appears at first sight since there is some evidence that vitamin $\mathrm{A}$ also has some influence on cone adaptation. Normal dark adaptation can be divided into two parts, an early adaptation, probably due to the cones, which is not very great in extent, and is complete in about seven minutes, and a later rapid and extensive adaptation which is due to the rods. Since most workers take their readings during the first ten minutes they may very well be testing cone adaptation only, even when they use an area of the retina which also contains rods. There is no doubt that the early cone adaptation is impaired by vitamin A deficiency though to a much less extent than the rod adaptation (Booher et al., Haig et al.) and Hecht and his colleagues believe that this effect on the curve indicates that vitamin A must be necessary for the formation of the cone substance in the same way that it is known to be necessary for the formation of visual purple. Whether this is so or not, it would seem to be more sensible, when testing for vitamin A deficiency by taking dark adaptation curves, to use a part of the retina which is known to 
contain rods and visual purple, even if to do so entails the spending of more time and trouble on the observations.

There is no doubt at all that variations from the normal dark adaptation curve can be used to diagnose vitamin A deficiency provided the test is made by experienced observers with suitable apparatus and over a sufficiently long period of dark adaptation. It is, however, extremely doubtful whether this particular method can ever be of any great value under the conditions which obtain when wide nutritional surveys of populations are attempted. In order to obtain a reliable dark adaptation curve the services of a skilled experimenter with elaborate apparatus are an absolute necessity and at least an hour is required for each individual test. These conditions are obviously not attainable when several hundred subjects have to be tested over a relatively short period.

\section{REFERENCES}

AYKROYD, W. R.-Lancet, Vol. CVIII, p. 824, 1930.

BAAS, K. L.-Arch. f. Ophthal., Vol. XL, p. 212, 1894.

Birnbacher, T., and Klaften, E.-Zeits.f. Augenheilk., Vol. LI, p. 309, 1923.

Blegvad, O.-Amer. Jl. Ophthal., Vol. VII, p. 89, 1924.

Bloch, C. E.-Amer. Jl. Dis. Child., Vol. XXVIII, p. 659, 1924.

Boll, F.-Ber. d. Akad. d. Wissensch. zu Berlin, p. 783, 1876.

Booher, L. E., Callison, E. C., and HEwston, E.-XVI Internat. Congress of Physiology, Zürich, 1938.

Bourne, M. C., CAMPBell, D. A., and TAnsley, K.-Brit. Jl. Ophthal., Vol. XXII, p. $613,1938$.

Chase, A. M.-Science, Vol. LXXXVII, p. 238, 1938.

Collins, E. Treacher.-Trans. Ophthal. Soc.U.K., Vol. XXXIX, p. 165, 1919.

DartNall, H. J. A., and Goodeve, C. F.-Nature, Vol. CXXXIX, p. 409, 1937.

Detwiler, S. R.-jl. Comp. Neurol., Vol. XXXVI, p. 125, 1923.

EDMUND, C., and CLEMMESEN, S.- " On deficiency of A vitamin and visual dysaptation." Oxford Univ. Pres:, 1937.

Ehlers, H.-Acta Ophthal., Vol. XV, p. 443, 1937.

FrANDSEN, H.-Hospitalstid., Vol. LXXVII (proc.), p. 42, 1934.

Fridericia, L. S., and Holm, E.-Amer. Jl. Physiol., Vol. LXXIII, p. 631925.

Garten, S.-Arch.f. Ophthal., Vol. LXIII, p. 112, 1906.

Greaves, J. D., and SchmidT, C. L. A.-Amer. Ji. Physiol., Vol. CXI, p. 502, 1935.

Groth-Peterson, E.-Acta Med. Skand., Vol. XCV, p. 110, 1938.

Guilbert, H. R., and HART, G. H.-Jl. Nutrit. Vol. VII1, p. 25, 1934.

GUilberT, H. R., and HART, G. H.-Jl. Nutrit., Vol. X, p 409, 1935.

Guilbert, H. R., Miller, R. F., and Hughes, E. H.Jl. Nutrit., Vol. XIII, p. $543,1937$.

HaIg, C.. HeCht, S., and PATEK, A. J.-Science, Vol. LXXXVII, p. 534, 1938.

Hart, G. H., MEAD, S. W., and Guilbert, H. R.-Proc. Soc. Exper. Biol. and Med., Vol. XXX, p. 1230, 1933.

Hart, G. H., and Guilbert, H. R.-Jl. Amer. Vet. and Med. Assoc., Vol. XCI, p. $193,1937$.

HEss, C.-Arch. f. Augenheilk., Vol. LXII, p. 50, 1909.

Holm, E,-Amer. Jl. Physiol., Vol. LXXIII, p. 79, 1925.

Hospitalstid., Vol. LXXXI, p. 139, 1929.

Jeans, P. C., and Zentmire, Z.-Ji. Amer. Med. Soc., Vol. CVI, p. 996, 1936.

Jeshers, H.-Jl. Amer. Med. Soc., Vol. CIX, p. 756, 1937.

KLAFTEN, E.-Zentralbi. f. Gynäk., Vol. XLVII, p. 1288, 1923.

KöNıG, A.-Sitzungsber d. K. Akad. d. Wissensch. zu Berlin (ii), p. 577, 1894.

KötTgen, E., and ABelsdorff. G.-Zeits. f. Physiol. u. Psychol. d. Sinnesorgan., Vol. VII, p. 161, 1896. 
Kolmer, W.-Zeits. f. d. ges. Anat., Abt. 1, Vol. XCIII, p. 679, 1930.

Krause, A. C., and Sidwf.Ll, A. E.-Amer. Jl. Physiol., Vol. CXXI, p. 215, 1938.

KRIES, J., v.-Arch.f. Ophthal., Vol. XLII, p. 95, 1896.

KÜHNE, W.-Heidelberg Physiolog. Untersuch., Vol. I, p. 1 et seq., 1877-78.

Lythgoe, R. J.-Jl. Physiol., Vol. LXXXIX. p. 331, 1937.

MAITRA, M. K., and HARRIS, L. J.-Lancet, Vol. CCXXXIII, p. 1009, 1937.

Mutch, J. R., and GRIfFith, H. D.-Brit. Med. Jl. (i), p. 565, 1937.

OSTERBERG, G.- " Topography of the layer of rods and cones in the human retina." Copenhagen, 1935.

OWen, H. B., and Hennessey, R. S. F.-Trans. Roy. Soc. Trop. Med. and Hyg., Vol. XXV, p. 367, 1932.

Palmer, C. E.-Amer. Jl. Pub. Health, Vol. XXVIII, p. 309, 1938.

PaRINAUD, M.-Compt. rend. d. l'Acad. d. Sci., Vol. XCIII, p. 286, 1881.

Purkinje, J.- " Neue Beiträge zur Kenntnis des Sehens in subjektiver Hinsicht." Berlin, 1825.

Schultze, M.-Arch.f. mikroskop. Anat., Vol. II, pp. 165 and 175, 1866.

Studnitz, G., v.-Pfiüger's Arch., Vol. CCXXX, p. 61.3, 1932.

- Pflüger's Arch., Vol. CCXXXIX, p. 515, 1937.

Sugita, Y.-Arch. f. Ophthal., Vol. CXV, p. $260,1925$.

TANsley, K.-Jl. Physiol., Vol. LXXI, p. 442, 1931.

- Proc. Roy. Soc., B., Vol. CXIV, p. 79, 1933.

- Biochem.Jl., Vol. XX, p 839, 1936.

Trendelen BuRg, W.-Ergebin. Physiol., Vol. XI, p. 1, 1911

VERHOEFF, F. H.-Arch. of Ophthal., Vol. V, p. 392, 1931.

WALD, G.-Jl. Gen. Physiol., Vol. XIX, p. 351, 1935.

Nature, Vol. CXL, p. 545, 1937.

Jl. Gen. Physiol., Vol. XXI, p. 795, 1938.

Walls, G. I.-Amer. Jl. Ophthal., Vol. XVII, p. 892, 1934.

WRIGHT, R. E - Lancet, Vol. CIX, p. 800, 1931.

\section{THE CHEMICAL EQUILIBRIUM OF THE INTERSTITIAL FLUIDS AND THE AQUEOUS HUMOUR*}

BY

J. Douglas Robertson, M.D.

LONDON

FROM THE COURTAULD INSTITUTE OF BIOCHEMISTRY,

MIDDLESEX HOSPITAL, W.I

THE chemistry of the various biological fluids is of importance, for chemical analysis is another method of determining the nature of the various fluids throughout the body. It is proposed to limit the discussion only to certain aspects of this problem, namely :-

1. The chemical equilibrium that exists between blood and lymph.

2. The chemical equilibrium that exists between blood and gastric juice.

3. The chemical equilibrium that exists between blood and the aqueous humour.

\footnotetext{
1938.

* Lecture delivered at the Royal London Ophthalmic Hospital, November 18,
,
} 